\title{
Do invisível labirinto da colonialidade à possibilidade de um feminismo decolonial: resenha da obra de Françoise Vergès*
}

\author{
Fernanda de Faria Viana Nogueira** \\ Júlia de Miranda Goromar***
}

De quem são os corpos violentados pelo trabalho de cuidar e limpar as cidades? Como a colonialidade se estrutura e reproduz (im)possibilidades nos corpos racializados das mulheres? Essas são algumas das inquietações que movem Françoise Vergès em sua primeira obra inédita no Brasil, intitulada Um Feminismo Decolonial (2020).

Ao ter crescido na Ilha da Reunião, departamento ultramarino francês localizado no continente africano, a autora traz as experiências de mulheres negras e racializadas para dar início à problemática central do livro: a colonialidade que se reverbera nas opressões vividas por essas mulheres. Foi sua experiência pessoal nessa Ilha, onde imperava uma ordem colonial francesa, que lhe permitiu entender a conexão entre capitalismo, racismo, sexismo e imperialismo. É nesse contexto que passa a desenvolver interesse pelas lutas emancipadoras e pôde percorrer uma trajetória anticolonial.

Partindo dessa realidade, mas também de uma experiência na França, a autora escancara as violências $e$ invisibilidades que os corpos das mulheres encarregadas do cuidado e da limpeza sofrem. A existência das más condições de trabalho; os assédios em seus ofícios; a vulnerabilidade à contaminação de doenças; a má remuneração - ou de muitas vezes da não remuneração - desse trabalho. Violações que geram a desumanização diária dessas mulheres que parecem não serem vistas nem mesmo por aquelas que, sendo também mulheres, compartilham da opressão de gênero. No que ela vai demonstrar e defender ser fundamental a invisibilização deste trabalho, tendo como fundamento a noção de que o capitalismo racial produz vidas supérfluas e não supérfluas.

Para adentrar nos feminismos de política decolonial é preciso, antes, demarcar que esse campo foi desenvolvido por meio de grupos e movimentos de teóricas/os do Sul Global. A partir de pensadoras como Gayatri Spivak, María Lugones, Lélia Gonzalez, Oyèrónké Oyewùmí, emergem teorias que extrapolam a conceituação de gênero, antes fundamentada em uma universalização de mulher. Essas autoras propõem um feminismo atento às experiências das mulheres que no passado $e$ no presente tiveram suas vidas apagadas pelo projeto de modernidade que chega com o homem branco, europeu, cristão, heterossexual. A necessidade de um contra-discurso é, portanto, um projeto que visa a descolonização dos olhares científicos unificadores que objetivam uma lógica dicotômica e categorial (Lugones, 2019).

Nesse sentido, uma das críticas que se pode fazer ao feminismo europeu é a que ele reproduz a colonialidade do poder e um sistema moderno/colonial de gêneros. Para os estudos decoloniais, a raça foi a categoria fundamental para a criação da modernidade, pois diferenciou humanos e nãohumanos e serviu como justificativa para a escravidão e a exploração dos povos tradicionais nas

\footnotetext{
* Recebida em 24 de setembro de 2020, aceita em 23 de novembro de 2020.

** Doutoranda em Geografia no Institudo de Geociências na Universidade Estadual de Campinas (Unicamp), Campinas, SP, Brasil. 262924@dac.unicamp.br / https://orcid.org/0000-0001-5848-4851

*** Graduanda em Direito na Faculdade de Direito da Universidade Federal Fluminense (UFF), Niterói, RJ, Brasil. Membro do Laboratório de Estudos Interdisciplinares em Direito Constitucional Latino-Americano (LEICLA), da mesma universidade. Aluna do curso de Especialização em Estudos Afro-latinoamericanos e caribenhos pela Faculdade Latino Americana de Ciências Sociais (FLACSO). juliagoromar@id.uff.br / https://orcid.org/0000-0003-0686-2907
} 
colônias. Na leitura das autoras Lugones e Oyewùmí, o gênero não perfazia uma categoria de poder $e$ de dominação no contexto dos povos tradicionais, que o relacionavam não somente ao sexo biológico, mas a outros fatores, a exemplo da idade.

Ao nos debruçarmos sobre importantes obras que por muito tempo ecoaram perspectivas sobre as mulheres, como "A dominação masculina" (1998) de Pierre Bourdieu, é possível observar a instauração de um patriarcado historicamente situado, no entanto, ainda com traços unificadores e homogeneizadores.

Para o teórico francês, a dominação masculina se desenvolve por meio de uma estrutura que é incorporada por esquemas inconscientes de percepção, fundada num sistema de oposições homólogas (alto/baixo; direita/esquerda; etc.) que tem como principal divisão aquela entre masculino e feminino (Bourdieu, 2019). Em contraposição, para teóricas como Oyèrónké Oyewùmí (2020) essa é uma visão necessariamente eurocêntrica, pois que na sociedade que toma como exemplo, a iorubá, não existia um sistema de gênero institucionalizado nem tampouco era o gênero um princípio de organização da sociedade iorubá antes de sua colonização.

Dessa forma, situando-se dentro do campo do feminismo decolonial, a autora nos apresenta um tipo de texto que mais se assemelha a um manifesto. Apesar de contar com uma vasta publicação propriamente acadêmica, Vergès não pretende nos apresentar toda uma bibliografia ou mesmo uma genealogia de um feminismo decolonial. $\mathrm{O}$ tipo de escrita nos deixa evidente que não se trata de uma tese acadêmica, mesmo que Vergès esteja ali defendendo um feminismo de política decolonial.

É colocando, portanto, suas preocupações nesse bojo de um labirinto invisível para a parte das mulheres brancas do Norte global que naturalizam e reforçam as opressões da colonialidade vividas pelas mulheres não-brancas situadas fora de uma realidade do Norte, que o texto tem o seu fio condutor.

Retomando as mulheres negras do Sul Global e racializadas que limpam a cidade, são elas o exemplo que Vergès toma para explicar a relação indissociável entre capitalismo, patriarcado, racismo e colonialidade. Trabalho este que, na França, foi originalmente exercido por mulheres do campo e da classe trabalhadora, passando para as mulheres escravizadas e depois às mulheres colonizadas. Hoje, grande parte do trabalho doméstico remunerado da França é feito por mulheres do Sul Global, muitas de antigos territórios colonizados, que ocorre por meio de um incentivo institucional francês pela imigração de jovens da Argélia, da Guiana, do Caribe e da Ilha da Reunião.

São os corpos dessas mulheres, negros, racializados e fatigados, que se ocuparão dos filhos e filhas de mulheres ricas, enquanto suas mães podem trabalhar no espaço público, acessar bens $e$ prazeres relacionados com sua classe social. Nesse sentido é que se compreende de imediato uma relação do capitalismo com a escravidão, pois que naquele momento em que se deu a divisão entre vidas vulneráveis e protegidas - entre humanos e não humanos. A permanência dessa divisão tratase da colonialidade. É ela que institui até hoje uma política de vidas descartáveis. Ademais, ressaltamos que a crítica sobre o colonialismo e o racismo que permeia o pensamento de Vergès (2020) não é inédita, pois, na construção do pensamento feminista negro podemos observar em sua gênese um movimento que se concentra criticamente também sobre essas estruturas de opressão.

Pensando no desenvolvimento dos movimentos feministas europeus, Vergès (2020) nomeia essa tentativa de libertação e emancipação em busca de uma igualdade de gênero que acontece na França e também no mundo, como um feminismo civilizatório. O feminismo civilizatório, dessa forma, é também considerado pela autora como aquele que busca uma universalização das mulheres, tirando o sentido de suas experiências e diferentes opressões - como as de raça, religião, nação, classe -, e acaba por reproduzir violências e invisibilizações sobre os corpos dessas mulheres que estão fora do bojo branco, europeu, cristão, de classe média. A autora nos mostra também que desde a época da colonização, as mulheres europeias, na tentativa de defenderem seus direitos civis e políticos, passaram a comparar-se com pessoas escravizadas, evidenciando a posição de que muitas se alinhavam às concepções colonialistas. 
É percebida então a dimensão colonial e racial desse feminismo europeu, que não escapou das ideologias racistas da escravatura nem da colonialidade. Não se tratando somente de um feminismo branco ou europeu, para ela, é o termo feminismo civilizatório que comporta essa dimensão a ser destacada porque evidencia uma técnica utilizada que é a de descivilizar o/a colonizado/a.

A autora se debruça, dessa maneira, na crítica a esse feminismo de matriz europeia que desenvolve uma cumplicidade com o capitalismo racial ao tolerar que algumas vidas sejam protegidas em detrimento de outras, estas últimas racializadas.

O que a autora movimenta com a categoria crítica de um feminismo civilizatório é justamente sobre onde devemos repousar nossa atenção, ou seja, na criação das falsas narrativas e também da falta das verdadeiras narrativas que sustentam a premissa de criação de uma Europa. E, ademais, como exposto por ela, um feminismo francês branco que, em sua gênese, solapa e uniformiza a vida das mulheres negras do Sul do mundo. É sobre uma compreensão de uma necessidade de salvação, de libertação individual que, muitas vezes, o feminismo civilizatório corrobora para extirpação do direito à existência das mulheres provenientes do Sul global.

Nesse ensejo também vale destacar que, mesmo sendo as responsáveis por cuidar dos filhos de seus patrões, da limpeza das empresas e dos transportes, a cidade é negada a essas mulheres. A metrópole se torna um espaço apenas de exploração. Mesmo as que a acessam com dificuldade, o fazem somente para o trabalho, que na maioria das vezes é desumanizado. Acessos e interdições à metrópole, assim, expõem que há uma evidente segregação espacial, pois, mesmo quando lhes é possivel estar nos grandes centros europeus, por exemplo, também ali são negadas as chances de viver fora de uma marginalização urbana.

A proposta de Vergès, desse modo, caminha na construção de alinhamento com um feminismo que lute pelo direito das mulheres do Sul Global existirem - sobretudo aquelas que nos precederam. Em acordo com as políticas decoloniais, a autora se alinha a um movimento que é contrário ao mascaramento da multiplicidade frente à uma ordem liberal. Nas palavras da autora, o feminismo decolonial pode ser entendido como “...a despatriarcalização das lutas revolucionárias [...] os feminismos de política decolonial contribuem na luta travada durante séculos por parte da humanidade para afirmar seu direito à existência." (p. 35).

Não existe um único feminismo decolonial. O emprego e escolha por um artigo indefinido um feminismo decolonial e não - o feminismo decolonial - não é um fato ao acaso, faz parte da compreensão de um movimento amplo, transnacional e plural, contraposto ao feminismo universalizante que é civilizatório. Necessariamente será um feminismo que é fiel às lutas das mulheres do Sul, sobretudo porque são essas lutas anticoloniais, revolucionárias, pela descolonização e de resistência à colonização que precederam um feminismo de política decolonial.

A crítica ao feminismo civilizatório hegemônico, aquele que se opõe de fato ao feminismo decolonial, está calcada no eurocentrismo dos discursos que ratificam e alimentam o sistema capitalista que atravessa e destrói a vida das mulheres racializadas não-europeias. Com a colonialidade que se espraia e se alinha com o capitalismo, seus saberes, experiências, técnicas e vidas são vistos e considerados desumanos pela ordem europeia em prol de uma civilidade não requisitada, que ao mesmo tempo também se apropria e falseia uma história/ordem mundial para essa sociedade. Dessa forma, a partir de um feminismo decolonial é necessário e possível pensarmos com urgência nas pedagogias que recuperem e construam histórias a partir de uma centralidade pautada nas narrativas do Sul global.

Os feminismos de política decolonial se inscrevem no amplo movimento de reapropriação científica e filosófica que revisa a narrativa europeia do mundo. Eles contestam a economiaideologia da falta, essa ideologia ocidental-patriarcal que transformou mulheres, negros/as, povos indígenas, povos da Ásia e da África em seres inferiores marcados pela ausência da razão, de beleza ou de um espírito naturalmente apto à descoberta científica e técnica. Essa ideologia forneceu o fundamento das políticas de desenvolvimento que, grosso modo, dizem: "vocês são subdesenvolvidos, mas podem se tornar desenvolvidos, desde que adorem nossas tecnologias, nossos modos de resolver problemas sociais e econômicos. Vocês devem imitar nossas democracias, o melhor dos sistemas, pois não sabem o que é liberdade, respeito pelas leis, separação de poderes (Vergès, 2020:39). 
Ao repousar seu olhar sobre as realidades vivenciadas no século XXI, a autora coloca também a necessidade de nos atentarmos às tentativas de anulamento das lutas feministas que o capitalismo se apropria de forma perspicaz. Assim, a proposição de uma abordagem revolucionária sofre com esse apagamento forçado, inclusive da história de personagens importantes para a luta anticolonial $e$ decolonial. Um feminismo decolonial que possua uma visão sistêmica e da totalidade das opressões, está ancorado nas lutas coletivas pela descolonização e de resistência ao colonialismo.

Sob a premissa de uma liberdade das existências, o feminismo civilizatório da atualidade também atravessa e invisibiliza outras vivências para além daquela que é tida como padrão. Para exemplificar, a autora demonstra a questão do islã e da islamofobia na França, relacionada com uma perseguição histórica ao Islã em que o mesmo passa a figurar como inimigo, citando exemplos atuais como a proibição do uso do véu em espaços públicos haver sido defendida por feministas francesas, que entendiam como ameaça aos seus direitos já conquistados, focando na sua liberdade individual. Por isso, em contrapartida à liberdade das francesas, a visão orientalista da submissão feminina a uma ordem extremamente masculina, tendo como sua representação máxima o uso do véu. Portanto, manifestaram-se contrariamente ao uso nos espaços públicos, invocando uma narrativa de missão civilizatória: libertar as mulheres muçulmanas.

Por trás disso, existe também a ideia de que os homens muçulmanos são misóginos por natureza, e a defesa da laicidade em ataque direto ao islamismo - religião que será considerada intrinsecamente sexista. E, com efeito, as mulheres muçulmanas vistas como frágeis são estimuladas a romper com essa lógica $e$ viver nos moldes ocidentais. Muitas delas foram incentivadas a conquistarem sua independência financeira por meio da realização do trabalho doméstico remunerado na própria França. Essa ideologia liberal alimenta o feminismo civilizatório permitindo uma associação ou aproximação das ideias feministas com ultranacionalistas e neoliberais islamofóbicos. A isso se deu o nome de femonacionalismo.

Outro ponto a ser abordado na obra é a (im)possibilidade das narrativas militantes que se colocam frente ao capitalismo neoliberal que destrói a vida das mulheres negras e racializadas do Sul Global. Exemplo disso é o embranquecimento de algumas figuras, e a despolitização de outras para que passem a ser toleráveis. Uma vez desassociadas do feminismo radical e da militância, mulheres militantes podem vir a ser aceitas e incorporadas nos discursos hegemônicos. Casos como o de Marielle Franco, vereadora negra e lésbica do estado do Rio de Janeiro assinada em 2018, dão ao texto da autora forma e cor para exemplificar as violências sofridas por milhares de mulheres que ocupam alguma posição de destaque e se opõem às dinâmicas impostas pelo capitalismo e eurocentrismo dos discursos.

A recuperação e a reescrita da história do feminismo é essencial para uma narrativa militante que foi pacificada e, por vezes, exterminada. Por isso, reescrever e recuperar faz parte de uma política decolonial que entende como primordial a reescrita da história do feminismo desde a colônia, tendo em vista que foi sua criação $e$ imposição que implicou nas instituições atuais estruturalmente racistas.

Seu objetivo é, portanto, um feminismo de política decolonial como imaginário utópico. Ao resgatar a luta dos/as quilombolas em resistência ao tráfico de pessoas e à escravidão, que representam uma promessa radical e de resistência, Vergès está pensando na desestabilização que esse movimento gera. É, então, um movimento que dá continuidade às lutas de emancipação das mulheres do Sul.

Um feminismo que, a um só tempo, se opõe às violências do capitalismo e ameaça o patriarcado. O feminismo de política decolonial proposto por Vergès é um pensamento de ação revolucionária, por isso uma utopia, que irá se opor a um feminismo antidiscriminatório incorporado pelo capitalismo, pois enxerga a relação entre patriarcado, capitalismo e racismo; $e$ dessa maneira é um feminismo decolonial porque se situa no combate à colonialidade do poder.

\section{Referências bibliográficas}

BOURDIEU, Pierre. A dominação masculina. $15^{\mathrm{a}}$ ed. Rio de Janeiro, Bertrand Brasil, 2019. Tradução de Maria Helena Kühner. 
LUGONES, María. Rumo a um feminismo descolonial. In: HOLLANDA, Heloísa Buarque de (org.). Pensamento feminista: conceitos fundamentais. Rio de Janeiro, Bazar dos Tempos, 2019.

OYÈRÓNKÉ, Oyewumi. Conceituando gênero: os fundamentos eurocêntricos dos conceitos feministas e o desafio das epistemologias africanas. In: HOLLANDA, Heloisa Buarque de (org.). Pensamento feminista hoje: perspectivas decoloniais. Rio de Janeiro, Bazar dos Tempos, 2020.

VERGÈS, Françoise. Um feminismo decolonial. São Paulo, Ubu Editora, 2020. Tradução de Jamille Pinheiro Dias e Raquel Camargo. 